\title{
Research
}

\section{Transient Social-Ecological Stability: the Effects of Invasive Species and Ecosystem Restoration on Nutrient Management Compromise in Lake Erie}

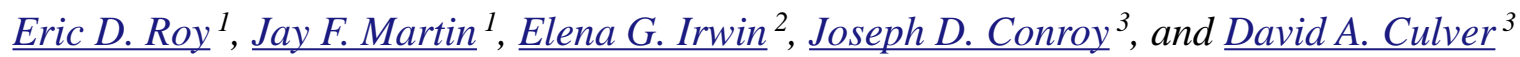

\begin{abstract}
Together, lake ecosystems and local human activity form complex social-ecological systems (SESs) characterized by feedback loops and discontinuous change. Researchers in diverse fields have suggested that complex systems do not have single stable equilibria in the long term because of inevitable perturbation. During this study, we sought to address the general question of whether or not stable socialecological equilibria exist in highly stressed and managed lacustrine systems. Using an integrated humanbiophysical model, we investigated the impacts of a species invasion and ecosystem restoration on SES equilibrium, defined here as a compromise in phosphorus management among opposing stakeholders, in western Lake Erie. Our integrated model is composed of a calibrated ecological submodel representing Sandusky Bay, and a phosphorus management submodel that reflects the societal benefits and costs of phosphorus regulation. These two submodels together form a dynamic feedback loop that includes freshwater ecology, ecosystem services, and phosphorus management. We found that the invasion of dreissenid mussels decreased ecosystem resistance to eutrophication, necessitating increased phosphorus management to preserve ecosystem services and thus creating the potential for a shift in social-ecological equilibrium. Additionally, our results suggest that net benefits in the region following the invasion of dreissenids may never again reach the pre-invasion level if on-site phosphorus control is the sole management lever. Further demonstrating transient system stability, large-scale wetland restoration shifted points of management compromise to states characterized by less on-site phosphorus management and higher environmental quality, resulting in a significant increase in net benefits in the region. We conclude that lacustrine SESs are open and dynamic, and we recommend that future models of these systems emphasize site-specific perturbation over equilibrium, thereby aiding the development of management plans for building system resistance to undesirable change that are both flexible and sustainable in an unknowable future.
\end{abstract}

Key Words: Dreissena; ecosystem services; invasive species; Lake Erie; lake eutrophication; lake management; perturbation; phosphorus

\section{INTRODUCTION}

Investigations of multiple equilibrium states in complex systems have occurred in various realms of scientific research. For example, Thornes (1983) has proposed an evolutionary geomorphology characterized by a shift "from the observation of equilibrium states per se to the recognition of the existence of multiple stable and unstable equilibria, the bifurcations between them and the trajectories connecting them." Massey (1999) highlights the importance of such a shift for natural sciences, social sciences, and the integration of the two. Researchers in thermodynamics (Prigogine and Stengers 1984), ecology (Holling 1996), human geography (Massey 1999), and economics (Buchanan and Vanberg 1994) have suggested that complex systems do not have single stable equilibria in the long term, and that perturbation is the norm, not the exception. The debate over the nature of time and stability is critical to the practice of modeling complex lacustrine social-ecological systems (SESs), among other systems. Increasingly, policy makers need tools for the management of lakes characterized by alternate

\footnotetext{
${ }^{1}$ Department of Food, Agricultural and Biological Engineering, Ohio State University, ${ }^{2}$ Department of Agricultural, Environmental and Development Economics, Ohio State University, ${ }^{3}$ Department of Evolution, Ecology and Organismal Biology, Ohio State University
} 
states and unique, unforeseeable perturbations. Generalized lake models are often presented as an investigation of the fundamentals of SES dynamics (Carpenter et al. 1999a). An alternative approach that builds upon generalized lake models is to conceptualize system behavior in terms of an event (Deleuze and Guattari 1987, Massey 1999). Events occur in specific locations at specific times under specific socioeconomic, political, and ecological constraints, and conceptualizing SES in terms of events involves a shift in focus from a potential equilibrium to inevitable perturbation.

The eutrophication of lakes is characterized by accelerated primary productivity compared with what would have occurred in the absence of perturbations (Wetzel 2001). Ecological consequences of lake eutrophication, including harmful algal blooms, oxygen depletion, and fish kills, negatively impact people in terms of reduced ecosystem services and increased economic costs (Wilson and Carpenter 1999). Algal blooms and fish kills create obvious impairments along coastlines that can detract from recreational activities, such as swimming, and low water clarity has been shown to have a substantial negative effect on housing values (Ara 2007). Ecosystems are managed, in part, to create socioeconomic opportunity by restoring or preserving the quality of ecosystem services (Holling 1996). Historically, lake eutrophication has largely been studied and managed in a manner that places emphasis on external loading of phosphorus (P) and nitrogen $(\mathrm{N})$. However, decreased nutrient input does not always result in an immediate or complete reversal of eutrophication (Sas 1989, National Research Council 1992, Cooke et al. 1993), and symptoms of eutrophication may reappear despite decreases in nutrient loads that had improved water quality in the past (Conroy et al. $2005 b$ ). In these cases, internal biophysical processes may increase eutrophication, illuminating poorly understood connections among energy pathways, ecosystem services, and nutrient management plans.

Conceptualizing lake management in a more holistic manner that integrates socioeconomics and ecology has led to several social-ecological models of eutrophication (e.g., Carpenter et al. 1999a, $b$, Ludwig et al. 2003, Hein 2006, Iwasa et al. 2007, Chen et al. 2009). However, the model we present here is among the first capable of analyzing an ecological perturbation unique to a specific system by simulating all three of the following simultaneously: (1) a trade-off between ecosystem services, i.e., nutrient-intensive food production and freshwater aesthetics and recreation, (2) a dynamic, continuous feedback loop between ecology and society that includes a multiparameter ecological submodel calibrated for a specific ecosystem, and (3) a measurable aesthetic and recreational ecosystem service that benefits society, i.e., water clarity. Although eutrophication is a widely occurring phenomenon, causes and effects are ultimately site specific (Jøgensen 1982), and dynamic two-way coupling is essential to addressing human behavioral responses to ecological change in lacustrine systems (Irwin and Geoghegan 2001).

To better understand the interaction between humans and ecological systems, we sought to identify the impacts of two ecological perturbations -(1) the invasion of dreissenid mussels, and (2) wetland restoration-on overall SES behavior in western Lake Erie. Equilibrium and stability are not well-defined concepts when applied to real-world ecological systems (DeAngelis and Waterhouse 1987, Grimm and Wissel 1997). Applying these concepts to SESs risks misleading readers with diverse backgrounds, so study-specific definitions must be clear. Here, we use "social-ecological equilibrium" to refer to the point at which a compromise in ecosystem management is reached between opposing stakeholders in a lake system (i. e., opposing stakeholder pressures for more and less management become balanced), producing a stable level of nutrient management within the lake's watershed and freshwater environmental quality that fluctuates solely because of climate forcing. For systems that tend toward an equilibrium (e.g., in our model, the system moves from an initial condition with unbalanced stakeholder pressures to a stable state with balanced stakeholder pressures), the equilibrium state is defined as an "attractor" (Walker et al. 2004). Therefore, we use "equilibrium" and "attractor" interchangeably depending on the context.

Several researchers have hypothesized that recent symptoms of eutrophication in western Lake Erie are the result of alterations to nutrient dynamics and ecosystem structure caused by dreissenid mussels (e.g., Hecky et al. 2004, Conroy et al. 2005a, Conroy et al. 2008). The dreissenid mussel invasion thus represents an unforeseen, initially external ecological perturbation with system-wide implications because of internal ecosystem impacts. Ecosystem 
restoration efforts may also be viewed as ecological perturbations. Over the past 200 yrs, approximately $95 \%$ of the wetlands surrounding western Lake Erie have been lost because of drainage and development (Mitsch and Gosselink 2007). Most of the coastal wetlands that remain along the Great Lakes today are diked, allowing human manipulation of water levels, including a large area (1,730 ha) of marshes where the Sandusky River meets Sandusky Bay. Mitsch and Wang (2000) found that restoring the original hydrology to these marsh areas has the potential to decrease the amount of phosphorus entering the bay by $12 \%$, and thus to alleviate eutrophication in Lake Erie.

The objectives of our modeling approach were to: (1) model water clarity as a specific freshwater ecosystem service, (2) represent social groups with opposing economic interests, (3) assess the impacts of a unique ecosystem perturbation on ecosystem stability properties, i.e., the invasion of dreissenid mussels, (4) investigate the effects of large-scale wetland restoration on whole-system behavior, and (5) identify existing research gaps. We combined a calibrated and validated ecological model with a simple phosphorus management model that reflects the societal benefits and costs of phosphorus regulation. These submodels together formed a simple, dynamic social-ecological model of the Sandusky Bay and watershed.

We present a site description, including the trophic history of western Lake Erie and its current state, a description of our integrated model, and the results of simulated system perturbations by invasive dreissenid mussels and a wetland restoration project. We use the results to identify recommendations for the management of western Lake Erie and for future approaches to modeling complex lacustrine SES.

\section{METHODS}

\section{The Study Site}

Lake Erie has experienced the greatest amount of human-related perturbation of all the Laurentian Great Lakes (Burns et al. 2005). Conversion of land to urban and agricultural uses increased nutrient loads to the lake gradually until about 1940 (Charlton et al. 1993). Agricultural activity, population growth, increased sewage discharge, and the wide-scale use of phosphate-containing detergents resulted in sharp increases in phosphorus loading from 1940 through the 1970s (DiToro et al. 1987, Charlton et al. 1993, Conroy et al. 2005b). As a result, the joint United States of America-Canada Great Lakes Water Quality Agreement was passed in 1972. This act set whole-lake phosphorus loading limits that were predicted to alleviate the symptoms of eutrophication, including central basin hypoxia, harmful algal blooms, and excessive total algal biomass (DiToro et al. 1987, McGucken 2000). During the 1980s, steady decreases in total algal biomass and cyanobacterial blooms suggested that reductions in external phosphorus loading were effective in restoring the lake (Makarewicz and Bertram 1991).

Currently, however, Lake Erie is "in a stage of transition, reflecting human and environmental influences acting simultaneously on a poorly understood system" (Matisoff and Ciborowski 2005). Standing algal biomass has been significantly greater in recent summers than between the mid-1980s and early 1990s (Conroy et al. 2005b, Conroy et al. 2008). Until the invasion of dreissenid mussels, the central role of excessive external phosphorus loading to the eutrophication of Lake Erie was clear. Although external phosphorus loading has not changed significantly since the 1980s (Dolan and McGunagle 2005), total phosphorus within the lake has increased (Makarewicz et al. 2000, Charlton and Milne 2004, Porta et al. 2005), as has phytoplankton biomass (Conroy et al. 2005b), leading researchers to speculate that the establishment of invasive dreissenid mussels may be responsible (Matisoff and Ciborowski 2005).

Zebra mussels (Dreissena polymorpha) and quagga mussels (Dreissena bugensis) entered Lake Erie during the late 1980s through ships' ballast water discharges (Hebert et al. 1989, May and Marsden 1992). By 1993, dreissenid mussel density at a western basin reference site was $>62,000$ zebra mussels $/ \mathrm{m}^{2}$, but quagga mussels had yet to become established. Since then, density has decreased, but individual weight and length have increased, and quagga mussels now dominate the dynamic dreissenid community (J. D. Conroy and D. A. Culver, unpublished data). Since the mussel invasion, nearshore symptoms of eutrophication have developed and/or intensified, including summer blooms of the cyanobacterium Microcystis sp. (Vanderploeg et al. 2001, Vincent et al. 2004, Conroy et al. 2005a, $b$ ) and the benthic filamentous 
Fig. 1. Landsat 7 true-color composite view of Sandusky Bay, the Sandusky sub-basin, and western Lake Erie.

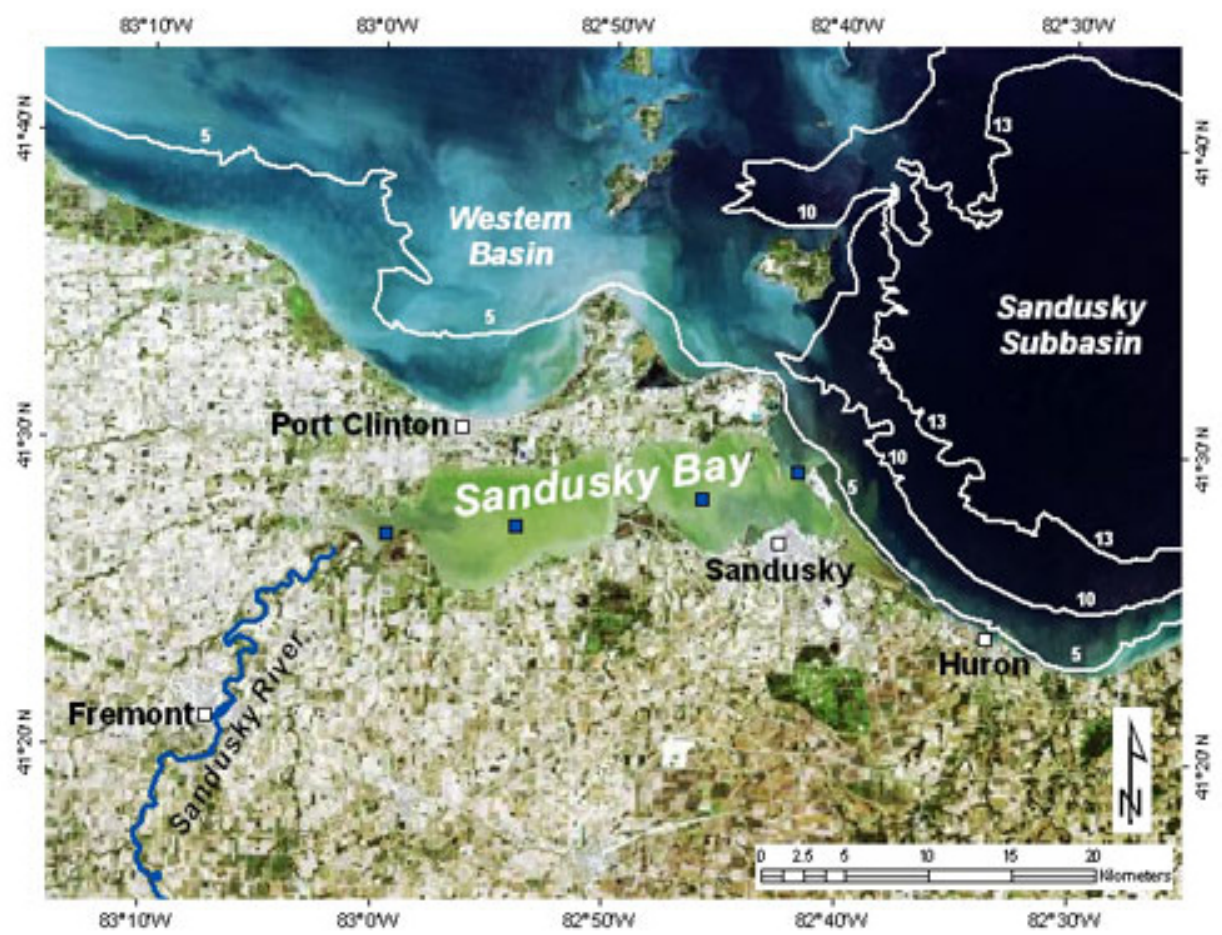

Note: Field sites used to calibrate the ecological model are represented by blue squares at the end of the Sandusky River (blue line), in the western and eastern portions of the bay, and at the bay and lake junction. Several cities in the region (white squares) and the 5-, 10-, and 13-m depth contours (white lines) in Lake Erie are shown. The base-map image (taken 19 June 2007) shows the high density of phytoplankton in Sandusky Bay (light green color), the mixed sediment/phytoplankton plumes entering from Sandusky River (darker green color), and the agricultural fields in the watershed (grey-brown color). The satellite image was taken by the National Aeronautics and Space Administration and provided courtesy of the OhioLINK Digital Media Center.

green alga Cladophora (Hecky et al. 2004), accompanied by increasingly high total phytoplankton biomass (Conroy et al. 2005b). The selective rejection of Microcystis sp. by dreissenids, extensive food web perturbations following the dreissenid invasion, and dreissenid phosphorus excretion that increases rates of phosphorus recycling, have all likely contributed to these changes (Vanderploeg et al. 2001, Hecky et al. 2004, Vincent et al. 2004, Conroy et al. 2005a,b, Edwards et al. 2005, Matisoff and Ciborowski 2005, Conroy et al. 2008).

A large degree of spatial heterogeneity and extensive data requirements meant that the complexity of developing an ecological model representing the entire western basin of Lake Erie was impractical for our preliminary interdisciplinary study. Therefore, we focused on Sandusky Bay, located on the southwest shore of Lake Erie, Ohio, USA (Fig. 1). Sandusky Bay has an area of $162 \mathrm{~km}^{2}$ (Center for Lake Erie Area Research 1975), an average depth of $2.6 \mathrm{~m}$ (Richards and Baker 1985), and a total volume of $0.423 \mathrm{~km}^{3}$ (Conroy 2007). Water enters the bay through the Sandusky River and flows through the bay into the Sandusky subbasin. Dreissenid mussels are currently scarce in Sandusky Bay, so we calibrated and validated the ecological model without accounting for mussels, making it possible to test the systemic implications of a mussel invasion as a perturbation to the calibrated ecological model and thereby capture 
dynamics observed in the western basin where mussels are abundant.

The Sandusky watershed's $3,700 \mathrm{~km}^{2}$ of land (Conroy 2007) is dominated by agriculture (approximately 85\%), with urban land use accounting for $<10 \%$ (Baker and Ostrand 2000). Nonpoint sources were responsible for somewhere between $91 \%-96 \%$ of the total phosphorus export to the bay between 1985-1995 (Forster et al. 2000). Using a model of farmland tillage practices and water quality, Forster et al. (2000) found that changes in nonpoint phosphorus loading were directly related to tillage method, illustrating the important link between farming practices and nutrient loading in the region. Sandusky Bay and its watershed play a substantial role as a conduit for nutrients and, in some instances, pulses of phytoplankton to Lake Erie. Therefore, the Sandusky region is a critical location for potential eutrophication mitigation strategies in the larger context of the Lake Erie ecosystem (Conroy 2007), and modeling the interactions among humans, the watershed, and the lake is appropriate for this site.

\section{The Integrated Social-Ecological Model}

We used STELLA 9.0 (isee Systems, inc.) to develop a social-ecological model including dynamic interactions among phosphorus management, ecology in Sandusky Bay, and ecosystem services (Fig. 2). Our integrated model is largely a "scoping model" and can be used to "understand how the system works, to analyze the relative importance of processes and connections in the system, and to identify gaps in experimental information," as opposed to a "predictive model" that is used to predict future parameter values as accurately as possible (Costanza and Voinov 2001). We coupled our two submodels, the Sandusky Bay ecological model and the phosphorus management model, through two connection points: (1) water clarity, measured as Secchi depth, and (2) external phosphorus loading from the Sandusky watershed. Our phosphorus management submodel simulates passive adaptive management, incorporating an automatic control system that varies its actions as parameter estimates change (Walters 1986). The management submodel has no predetermined experimental management action, but adjusts in response to stakeholder pressures resulting from ecological conditions and phosphorus management levels. The integrated model has a total runtime of
50 yrs and both submodels run on a daily time step. Daily water clarity output and the corresponding benefits level are continuously collected within the model, and a seasonal mean environmental benefits value is calculated each year. At 5-yr intervals, the five seasonal environmental benefits values related to water clarity are averaged and, along with a 5-yr mean production benefits value corresponding to the current level of phosphorus management, used to determine respective stakeholder pressures and a positive or negative change in management. Management then remains constant for $5 \mathrm{yrs}$, impacting each day's external phosphorus load, until another evaluation takes place. We model phosphorus as soluble reactive phosphorus (SRP), or phosphate-phosphorus, a form readily available to algae. Therefore, all references here to phosphorus management and phosphorus dynamics refer more specifically to SRP.

\section{Sandusky Bay Ecological Model}

Our ecological submodel represents $1 \mathrm{~m}^{3}$ of water in the Sandusky Bay that is characterized by baywide spatial mean values for all variables (i.e., a well-mixed reactor). All concentrations are calculated in terms of the $1-\mathrm{m}^{3}$ volume, and forcing function values are scaled accordingly. We adapted the lower trophic level equations from those utilised in the Lake Michigan ecosystem model developed by Limno-Tech, Inc. (2000). We model populations of algae that are edible to zooplankton, algae that are inedible to zooplankton, and crustacean zooplankton using mass balance equations. We then use total algal biomass to determine chlorophyll $a$ concentration and, subsequently, water clarity. All ecological nonlinearities occurring in simulations, aside from dreissenid mussel invasion scenarios, are solely a result of the forcing functions and internal relationships described below.

Forcing functions in our ecological submodel include water temperature, Sandusky River discharge, and Sandusky River SRP load. We used one 5-yr block of daily forcing function data to create a looped 50-yr data set that drives the integrated model and simulates a pattern of climatic variability (Appendix 1). Our full ecological submodel is presented in Appendix 2.

Water clarity has previously been used in freshwater ecosystem services valuation (Steinnes 1992, Michael et al. 1996, Ara 2007). Ara (2007) found a 
Fig. 2. Integrated model network diagram. We show forcing functions and internal components as circles and boxes, respectively.

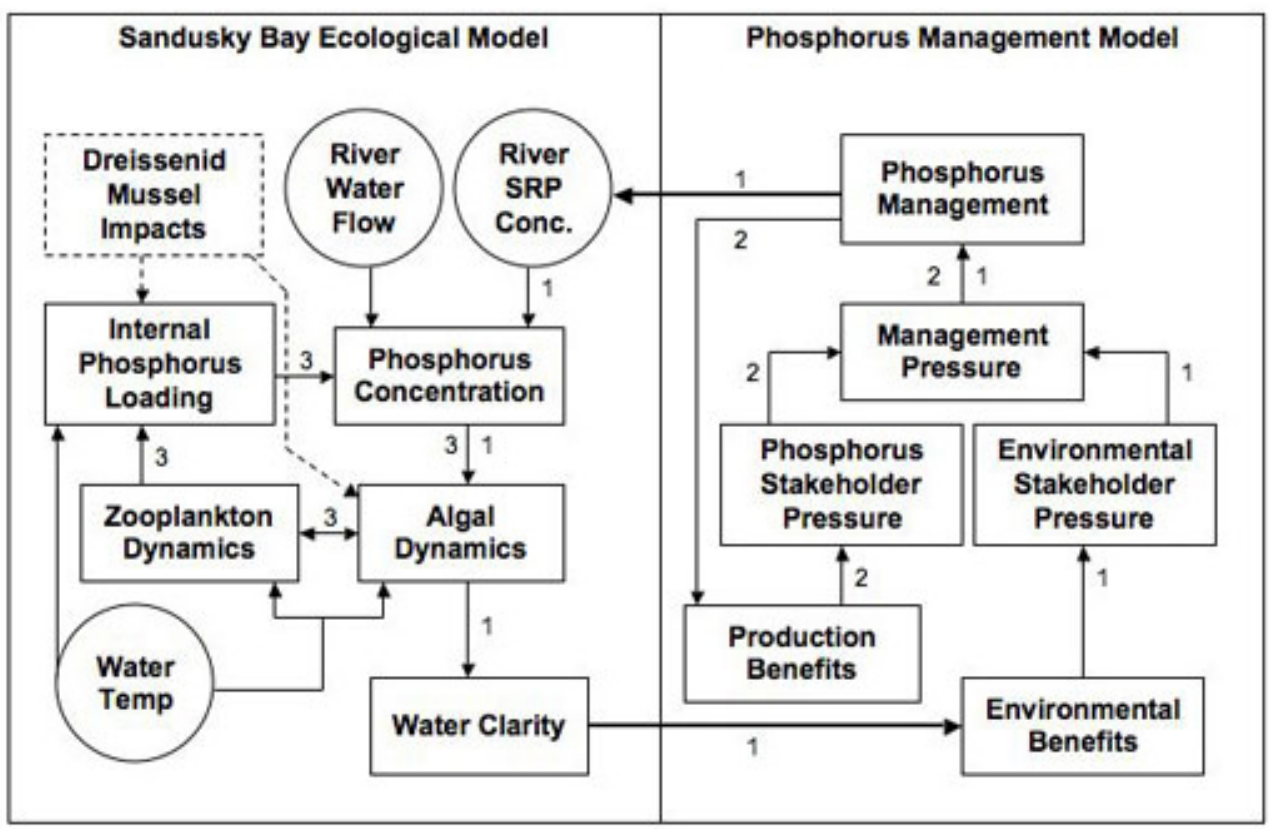

Note: Production benefits $\left(B_{p}\right)$ are the economic benefits associated with phosphorus loading and environmental benefits $\left(B_{e}\right)$ are the economic benefits associated with environmental quality, measured here by water clarity. The numbers 1,2 , and 3 indicate the three feedback loops within the integrated model. Feedback loop 1 couples the Sandusky Bay ecological model with the phosphorus management model. In this loop, river-soluble reactive phosphorus (SRP) load drives a lower trophic-level model that determines water clarity. This water clarity output determines $B_{e}$ which then determines environmental stakeholder pressure, influencing both management pressure and phosphorus management change. Completing the loop, river SRP load is automatically adjusted to reflect changes in phosphorus management. Feedback loop 2 captures the cycle where changes in phosphorus management alter $B_{p}$, determining phosphorus stakeholder pressure and influencing both management pressure and phosphorus management change. Feedback loop 3 exists within the lower trophic level of the ecological model. Phosphorus concentration drives algal dynamics that, in turn, drive zooplankton dynamics. Zooplankton population size determines the quantity of internal phosphorus loading due to excretion, affecting the future phosphorus concentration. Invasive dreissenid mussels impact the social-ecological system by influencing feedback loop 3 (dashed lines).

positive relationship between Lake Erie water clarity and adjacent housing values. In addition, Hein (2006) used water clarity as the measure of ecosystem services in an ecological-economic eutrophication model. Water clarity may be approximated by Secchi depth, a common limnological measurement that is measured by lowering a black and white disk into the water until it disappears from sight. Higher Secchi depth values represent clearer water (Wetzel 2001). Secchi depth served as the measure of the quality of freshwater ecosystem services within our integrated model.
We calibrated and validated our Sandusky Bay ecological model using measured SRP concentration, chlorophyll a concentration, Secchi depth, zooplankton biomass, and zooplankton phosphorus excretion data for 2005 and 2006, respectively. During these years, data were collected at four sites in the bay (Fig. 1). For each day that data were collected at all four locations, we compared baywide spatial mean values with model output for model calibration and validation both visually (i.e., by comparing plots of measured and modeled data) and quantitatively by calculating the best-fit linear 
regression $\left(r^{2}\right)$ between measured and modeled data, as is commonly used to assess a model's ability to predict time-series data accurately (Costanza 1989). Secchi depth proved to be difficult to estimate accurately on a daily basis because of the limited accuracy of Secchi depth measurements and variability in the relationship between chlorophyll $a$ and water clarity. Given our focus on seasonal averages in the evaluation of Secchi depth as an ecosystem service, we decided that calibration and validation standards based on seasonal means were sufficient. Calibration and validation were iterative processes that required numerous adjustments to model parameters.

\section{Phosphorus Management Model}

Eutrophication in western Lake Erie is an environmental issue largely characterized by the actions and perspectives of two societal groups that Scheffer et al. (2000) and Brock and Starrett (2003) broadly refer to as "affectors" and "enjoyers." Following Scheffer et al., we define "affectors" as those societal members whose economic activity results in an increase in lake pollution through loading significant amounts of phosphorus. Agricultural operations, construction firms, septic systems, and green lawn maintenance all generate economic benefits from activities that result in increased phosphorus loading to surface waters (Ludwig et al. 2003). We refer to these economic benefits as production benefits $\left(B_{p}\right)$. In the Sandusky watershed, the agricultural community, currently accounting for approximately $85 \%$ of land use (Baker and Ostrand 2000), is the dominant group of affectors. "Enjoyers" are lake users that benefit from the ecosystem, but do not significantly affect its conditions. This group includes coastal homeowners, recreational lake users, and local firms that serve recreational lake users (Scheffer et al. 2000). We specify economic benefits to enjoyers as environmental benefits $\left(B_{e}\right)$. Environmental benefits are dependent upon the condition of the ecosystem in question (Carpenter et al. 1999b, Ludwig et al. 2003). We also determine total net benefits $\left(B_{n e t}\right)$ as a function of $B_{p}$ and $B_{e}$ that represents overall economic welfare in the Sandusky region (Appendix 3).

Economic equilibrium is typically defined as an optimum social welfare point where marginal costs and benefits for opposing groups are equalized (Brock and Starrett 2003). However, when addressing ecosystem management problems, a regulating authority will typically respond to political pressures from affectors and enjoyers rather than seek an overall economic welfare optimum (Scheffer et al. 2000). Magee et al. (1989) derive political pressure supply functions for both sides of a conflict regarding pollution tax as Nash equilibria from a noncompetitive game model. In their model, pressures from affectors and enjoyers, respectively, against and in favor of raising a pollution tax, are determined by comparing benefits at a given tax level to reference benefits where the tax is equal to zero. Their model converges upon the point at which the opposing stakeholder pressures are equalized (also see Scheffer et al. 2000). Reference values have also been used in previous studies to define "restored" ecosystem conditions where the perceived environmental impact of affectors on $B_{e}$ is zero relative to expectations (White and Walker 1997, Wirl 2004, Iwasa et al. 2007). Our methodology in this study is inspired by the nutrient tax optimization model presented in Magee et al. (1989) and Scheffer et al. (2000), although changes were necessary here to simulate automatic, dynamic coupling of ecology and decision making. Similar to those previous models, our integrated model converges upon a social-ecological equilibrium defined as the point at which opposing nutrient management stakeholder pressures become equal.

Our phosphorus management submodel translates $B_{e}$ and $B_{p}$ values into opposing environmental and phosphorus stakeholder pressures, respectively, by comparing modeled values at each decision making iteration to reference benefits values, i.e., $B_{e}$ at restored ecosystem conditions and $B_{p}$ at initial conditions. These stakeholder pressures, along with respective political powers, together determine changes in phosphorus management, measured as the percent external phosphorus load reduction $(L R)$, every 5 yrs. (See Appendix 3 for full submodel descriptions.) These management changes modify ecosystem conditions that, in turn, determine future benefits, creating a feedback loop (i.e., feedback loop 2 in Fig. 2). Here, increased phosphorus management broadly reflects: (1) the adoption of strategies aimed at reducing initial phosphorus input from affectors such as fertilizer taxation or restriction on upland corn, wheat, and soybean fields, and (2) slowing the movement of upland phosphorus into surface waters, reducing the magnitude of phosphorus pulses to the bay during high flow events. We assume that all increases in 
phosphorus management result in decreases to $B_{p}$. Riparian buffers, bioswales, wetland creation and restoration, and stream restoration have all been specifically recommended for use in the Lake Erie watershed to combat eutrophication (Mitsch and Wang 2000, Loftus et al. 2006, Riddle et al. 2006). Other specific recommended methods for increasing the nutrient efficiency of agriculture in the Lake Erie watershed include no till, strip till, or conservation tillage, as well as cover crops and alternative crop rotations (Stonehouse 1999, Forster et al. 2000, Loftus et al. 2006, Riddle et al. 2006).

\section{System Perturbation 1: Dreissenid Mussel Invasion}

Recent research has suggested that internal phosphorus recycling by dreissenid mussels may have decreased the amount of external phosphorus loading needed to produce eutrophication symptoms, thereby altering ecosystem stability properties (Conroy and Culver 2005). We created two impact factors to simulate the effects of dreissenid mussels within the ecological model: (1) the mussel phosphorus excretion factor $(M E F)$, and (2) the mussel edible algae consumption factor $(M C F)$. The $M E F$ represents the additional internal phosphorus loading because of mussel phosphorus excretion relative to zooplankton phosphorus excretion (that was present before dreissenid establishment in the lake). Phosphorus recycling is represented in the model by:

$$
P_{\text {recycle }}=M E F^{*} E p
$$

where $P_{\text {recycle }}=$ internal phosphorus loading $(\mathrm{g} /$ day $^{-1}$ ) and $E p=$ zooplankton phosphorus excretion rate $\left(\mathrm{g} / \mathrm{day}^{-1}\right)$.

Therefore, $M E F=1.00$ indicates pre-mussel conditions. As $M E F$ is increased to values above 1.00 , internal phosphorus loading increases relative to zooplankton excretion, resulting in more phosphorus available to inedible and edible algae. Conroy et al. (2005a) report excretion rates for western Lake Erie indicating $M E F$ values of 1.31 for 1998 and 1.29 for 2003. Other researchers have reported higher $M E F$ values, closer to 2.0 (Arnott and Vanni 1996). Additionally, the presence of dreissenid mussels has been hypothesized to promote algal growth in ways other than direct phosphorus excretion. Decreased phosphorus turnover time, nitrogen recycling (Conroy et al. $2005 a$ ), and the relatively low nitrogen:phosphorus ratio of mussel excreta (Arnott and Vanni 1996, Raikow et al. 2004, Conroy et al. 2005a) have all been linked to increased primary production. The two dreissenid impacts related to nitrogen are particularly important contributors to blooms of Microcystis sp. To account for uncertainty regarding the impacts of mussels on phosphorus recycling and algal growth, we tested several $M E F$ values between 1.0 and 2.0.

The $M C F$ represents the amount of increased consumption of edible algae attributed to dreissenid mussels relative to zooplankton consumption rates. We represented this in the model by:

$$
\text { Pred }=\text { ZPred }{ }^{*} \text { MCF }
$$

where Pred $=$ total edible algae mortality from predation $\left(\right.$ day $\left.^{-1}\right)$ and ZPred $=$ edible algae mortality solely from zooplankton $\left(\right.$ day $\left.^{-1}\right)$.

Therefore, $M C F=1.00$ represents pre-mussel conditions. As $M C F$ is increased to values above 1.00 , Pred is increased at a rate relative to zooplankton predation. To isolate the effects of varying $M E F, M C F$ was estimated as 1.25 for most of the dreissenid mussel simulations for which results are presented below. However, we also performed a sensitivity analysis to gauge the effects of $M C F$ on the external phosphorus load reduction at which stakeholders reach a compromise. A similar impact factor was not applied to the inedible algae stock because studies have shown that dreissenid mussels selectively reject the inedible cyanobacterium Microcystis sp., facilitating bloom events (Vanderploeg et al. 2001). In addition, dreissenid mussels promote the growth of the filamentous alga Cladophora (Hecky et al. 2004), another species classified here as inedible.

We performed two sets of simulations to examine SES response to the internal ecosystem impacts of the initially external dreissenid mussel perturbation, i.e., their introduction into Lake Erie. In the first set of simulations, we set $M E F$ and $M C F$ at constant values for all $50 \mathrm{yrs}$ simulated, allowing the identification of social-ecological equilibria under several parameter configurations. In the second set of simulations, we simulated gradual dreissenid 
mussel invasions to represent a social-ecological perturbation. In these simulations, $M E F$ and $M C F$ were held constant at 1.00 for yrs $1-30$, and then increased using a linear ramp function between yrs 30-40, after which mussel effects were stabilized for the remainder of the $50-\mathrm{yr}$ simulation. These gradual invasions beginning at yr 30 gave the system time to approach stakeholder compromise before internal ecosystem perturbation. The $10-\mathrm{yr}$ period of change between yrs 30-40 was intended to represent an invasion similar to the one that occurred in western Lake Erie between the mid-1980s and mid-1990s.

The integrated model simulations of dreissenid mussels effects presented here specifically address the system's stability property known as "ecosystem resistance," defined as an ecosystem's ability to remain essentially unchanged despite the presence of disturbances (Grimm and Wissel 1997). Ecosystem resistance is identical to "resilience" as defined by Holling (1973), but differs slightly from more recent definitions of that term (see Grimm and Wissel 1997). Disturbances are already represented in our model by episodic periods of increased external phosphorus loading associated with climate, e.g., wet years. Therefore, ecosystem resistance here refers to the bay's capacity to absorb increased external phosphorus loading events without showing symptoms of eutrophication, represented by poor water clarity. Increases in internal phosphorus recycling from dreissenids potentially limit this capacity, decreasing the external phosphorus load needed to cause a poor water clarity event (Conroy and Culver 2005).

\section{System Perturbation 2: Wetland Restoration}

We simulated wetland restoration to investigate the impacts of large-scale ecosystem restoration strategies on the Sandusky SES. The wetland restoration proposed by Mitsch and Wang (2000) is an example of a mitigation strategy that may decrease the need for costly nonpoint source phosphorus management on upland agricultural fields while simultaneously decreasing the symptoms of eutrophication. To simulate the effects of restoring natural hydrology to the wetlands at the mouth of the Sandusky River, we included an initial $12 \%$ decrease in external phosphorus loading based on the estimate from Mitsch and Wang (2000). Therefore, for the entire 50-yr simulation, external phosphorus loading is reduced by $12 \%$ in addition to management changes occurring on the basis of stakeholder pressure. The impact of this phosphorus decrease on system behavior was assessed without mussels $(M E F=1.00$ and $M C F=1.00)$ and for all constant mussel simulations $(M E F>1.00, M C F>$ $1.00)$.

\section{RESULTS}

\section{Calibration and Validation of the Ecological Model}

The coefficients of correlation $\left(r^{2}\right)$ between measured and modeled values for chlorophyll $a$ concentration, zooplankton biomass, and zooplankton phosphorus excretion were $>0.80$ in all cases for 2005 and 2006 (Fig. 3). In 2005, our calibrated model estimated measured phosphorus dynamics very well $\left(r^{2}=0.87\right)$. Although phosphorus was predicted less accurately in the 2006 validation $\left(r^{2}=\right.$ 0.68 ), we decided that this level of correlation was sufficient for our objectives. Measured and modeled values for seasonal mean Secchi depth were not significantly different for either $2005(0.50 \pm 0.01$ $\mathrm{m}$ and $0.52 \pm 0.01 \mathrm{~m}$, respectively) or $2006(0.42$ $\pm 0.03 \mathrm{~m}$ and $0.46 \pm 0.06 \mathrm{~m}$, respectively). In summary, our ecological model, although simple, adequately captured field dynamics essential to testing the system perturbations described here. All final model parameters and associated literature values are presented in Appendix 4.

\section{Calibration of the Phosphorus Management Model}

Scheffer et al. (2000, Fig. 4) illustrate SESs with both concave and convex benefits-management relationships. In a SES with an entirely concave benefits-management relationship, there is a single net benefits optimum at an intermediate level of pollution management, indicating that a compromise between affectors and enjoyers yields the highest overall welfare. Alternatively, in a SES with an entirely convex benefits-management relationship, there are two local net benefits maxima representing biased situations that maximize the welfare of either affectors or enjoyers. Whether the relationship between net benefits and management in a SES is concave or convex depends on the precise shape of the ecosystem response curve. Because of the hypereutrophic nature of Sandusky Bay, our integrated model produced a benefits-management 
Fig. 3. Ecological model calibration (a) and validation (b) results using data from Sandusky Bay in 2005 and 2006, respectively.
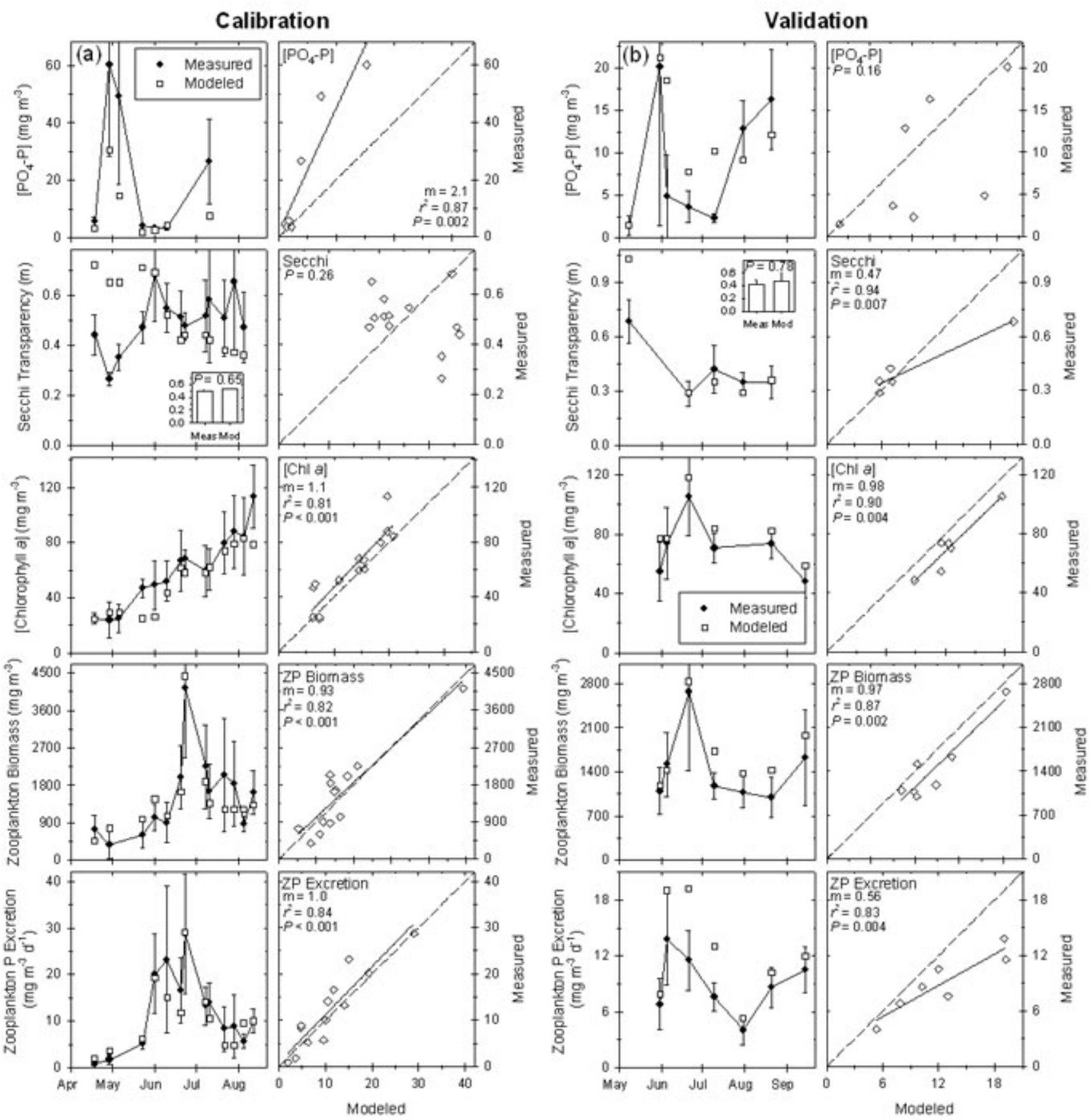

Note: The left panels of the graphs for each year show both measured and modeled seasonal dynamics using bay-wide spatial mean values ( \pm one standard error for measured data). The bar graph in the left panel for Secchi depth illustrates temporal means. The right panels show measured values predicted by modeled values (diamonds) with linear regression fits (solid line) if significant $(P<0.05)$ and the identity line (dashed). 
Fig. 4. Phase space showing environmental benefits $\left(B_{e}\right)$ as a function of percent external phosphorus load reduction $(L R)$, which is inversely related to production benefits $\left(B_{p}\right)$, with no mussels $(M E F=1.00$ and $M C F=1.00$ ) and with added mussel excretory and consumptive effects (e.g., $M E F>1.00$ and $M C F$ $=1.25)$.

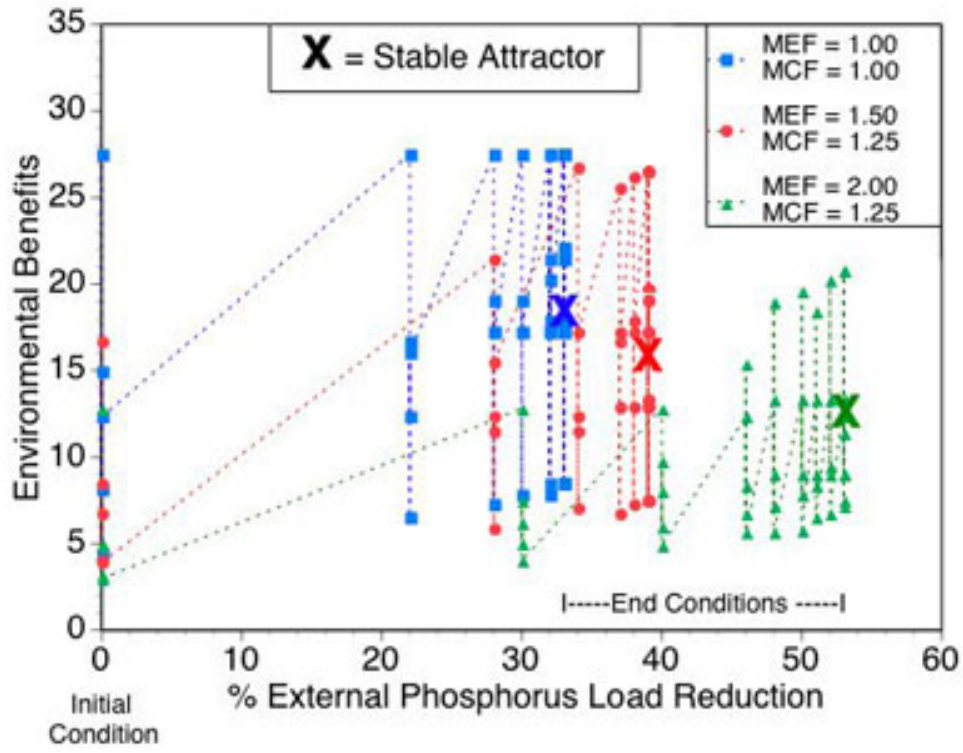

Note: Mussel effects were held constant at the specified levels over the entire 50 simulation yrs for each simulation. Individual data points (indicated by various symbols) show each of the 50 simulation yrs. Dotted lines illustrate the system's trajectory with time. In each case, the system began at $L R=0$ and $L R$ increased with time until stakeholder compromise (i.e., social-ecological equilibrium) was achieved. We label these attractors for the various simulations by the letter " $X$ " in bold. The trend in attractors illustrates the impact of decreasing ecosystem resistance (caused by increasing the magnitude of the mussel excretory impact) on system behavior.

curve under calibration parameter configurations (Appendix 4) that was initially convex at lower levels of phosphorus management, (i.e., there was little to no ecosystem response to small phosphorus load reductions), and then concave at higher levels of management, (i.e., the ecosystem responded positively at higher management levels), producing a local or global net benefits maximum before losses to affectors again became too great to be compensated for by increased environmental benefits. In the perturbation simulations presented below, we encountered a variety of cases in which the shape of the benefits-management curve ranged from fully convex, because of the significant impacts of invasive mussels on phosphorus dynamics, to fully concave, because of increased phosphorus sequestration within the watershed through wetland restoration.
Because our phosphorus management model is based on a general notion of benefits that is used to determine economic trends as opposed to exact economic values, we did not calibrate it by using measured data. However, we defined parameters within the phosphorus management model so that the baseline integrated model $(M E F=1.00, M C F=$ 1.00 , no wetland restoration) converged upon a social-ecological equilibrium where final $B_{n e t} \approx$ initial $B_{\text {net }}$ (Appendix 4). The benefits-management curve in this case was convex, with socialecological equilibrium occurring at $L R=33 \%$. This specification allowed us to easily identify trends in benefits variables during simulated system perturbations, e.g., changes in the shape of the benefits-management curve and the location of net benefits maxima. We present these dynamics in more detail below. 


\section{System Perturbation 1: Invasive Dreissenid Mussels}

Before presenting observed model behavior, we will clarify certain terms and presentation methods. The behavior of nonlinear models is typically described by plotting trajectories in a phase space (Byers and Hansell 1996). A phase space is a plotted space whose dimensions represent state variables of the model other than time. Trajectories, or "transitional dynamics," in this type of plot are represented by a sequence of points, each of which represents the values of the state variables at a given time $(t)$. Plotting results in a phase space allows the identification of system equilibrium states, also called "attractors." We are interested here in socialecological attractors that represent a nutrient management compromise between affectors and enjoyers. Figures 4, 6, 7, and 8 below all depict phase spaces in which social-ecological attractors are shown, with a benefits state variable on the $y$-axis and a phosphorus management state variable on the $x$-axis.

\section{SES parameter dependence for $M E F$ and $M C F$}

For the calibration model $(M E F=1.00, M C F=$ 1.00 ), increased phosphorus management resulted in a reduction of year-to-year variation in $B_{e}$, higher mean $B_{e}$, and decreased $B_{p}$ over time. Once the system achieved social-ecological equilibrium, $L R$ remained stable for the remainder of the simulation (Fig. 4). Year-to-year variation because of climate forcing was significant regardless of the value of $L R$ and the magnitude of changes in both $B_{e}$ and $B_{\text {net }}$ caused by weather were greater than those caused by increased phosphorus management.

Figure 4 also shows transitional dynamics and SES attractors for two alternative mussel parameter configurations in addition to the calibration case, illustrating that decreases in ecosystem resistance to eutophication produce SES attractors characterized by lower benefits of all types. The pre-management period for $M E F=1.50$ and $M C F=1.25$, i.e., the first 5-yr period when $L R=0$ (Appendix 4), was characterized by lower mean $B_{e}$ with less year-toyear variation compared with the control. This was caused by an increased occurrence of poor water clarity events, indicating lower ecosystem resistance to eutrophication. Increased phosphorus management resulted in increased mean $B_{e}$ and increased year-to-year variation in $B_{e}$ (Fig. 4). In this case, social-ecological equilibrium was characterized by a higher level of management (lower $B_{p}$ ) and lower $B_{e}$ than the attractor found for the calibration model.

Doubling internal phosphorus recycling because of dreissenids $(M E F=2.00, M C F=1.25)$ had a more pronounced impact on transitional dynamics compared with the test where $M E F=1.50$. Premanagement mean $B_{e}$ was lower and more phosphorus management was required to increase mean $B_{e}$ (Fig. 5). Social-ecological equilibrium occurred at a higher management level (lower $B_{p}$ ) with lower $B_{e}$ than the other two tests shown. Sensitivity analysis of $M C F$ indicated that, even when mussels were assumed to eat relatively large amounts of edible algae, ecosystem resistance still decreased in nearly all cases that included dreissenid excretory effects (Table 1).

Decreases in ecosystem resistance caused by invasive dreissenids found here created conditions where $B_{n e t}$ declined with increasing mussel phosphorus excretion (Fig. 6, solid lines). Maximum $B_{\text {net }}\left(B_{\max }\right)$ occurred at $L R=42 \%, 53 \%$, and $60 \%$ for $M E F=1.00,1.50$, and 2.00, respectively. The relationship between $B_{n e t}$ and $L R$ was initially convex without mussel impacts included $(M E F=M C F=1.00)$, indicating that initial management efforts (i.e., $0 \leq L R \leq 30 \%$ ) did not result in $B_{e}$ increases large enough to offset losses in $B$. This highlights the nonlinear nature of ecosystem response to phosphorus load reductions. Whether the relationship between $B_{n e t}$ and $L R$ was initially convex or concave was dependent on the magnitude of the dreissenid excretory impact. For $M E F=1.50$ and $M C F=1.25$, the benefitsmanagement relationship was concave and a global $B_{\text {max }}$ at $L R=53 \%$ was greater than $B_{n e t}$ at $L R=0 \%$. However, when $M E F=2.00$ and $M C F=1.25$, the relationship between $B_{n e t}$ and $L R$ was again convex and the positive difference between a local $B_{\max }$ at $L R=0$ and a local $B_{\text {max }}$ at $L R=60 \%$ was less significant $(<10 \%$ greater at $L R=60 \%)$, indicating that increased on-site phosphorus management produced little gains in $B_{n e t}$ when internal phosphorus recycling through animal excretion was doubled. A final, important result to note in Fig. 6 is that the global $B_{\max }$ values for the two mussel simulations were lower than the initial $B_{n e t}$ at $L R=$ $0 \%$ in the calibration case that excluded mussel effects. 
Fig. 5. Total net (green), production (red), and environmental (blue) benefits and management level (black) for simulations without mussels $(M E F=1.00$ and $M C F=1.00$; top panel) and with increased mussel excretory effects $(M E F>1.00)$ and added mussel consumptive effects $(M C F>1.00)$.
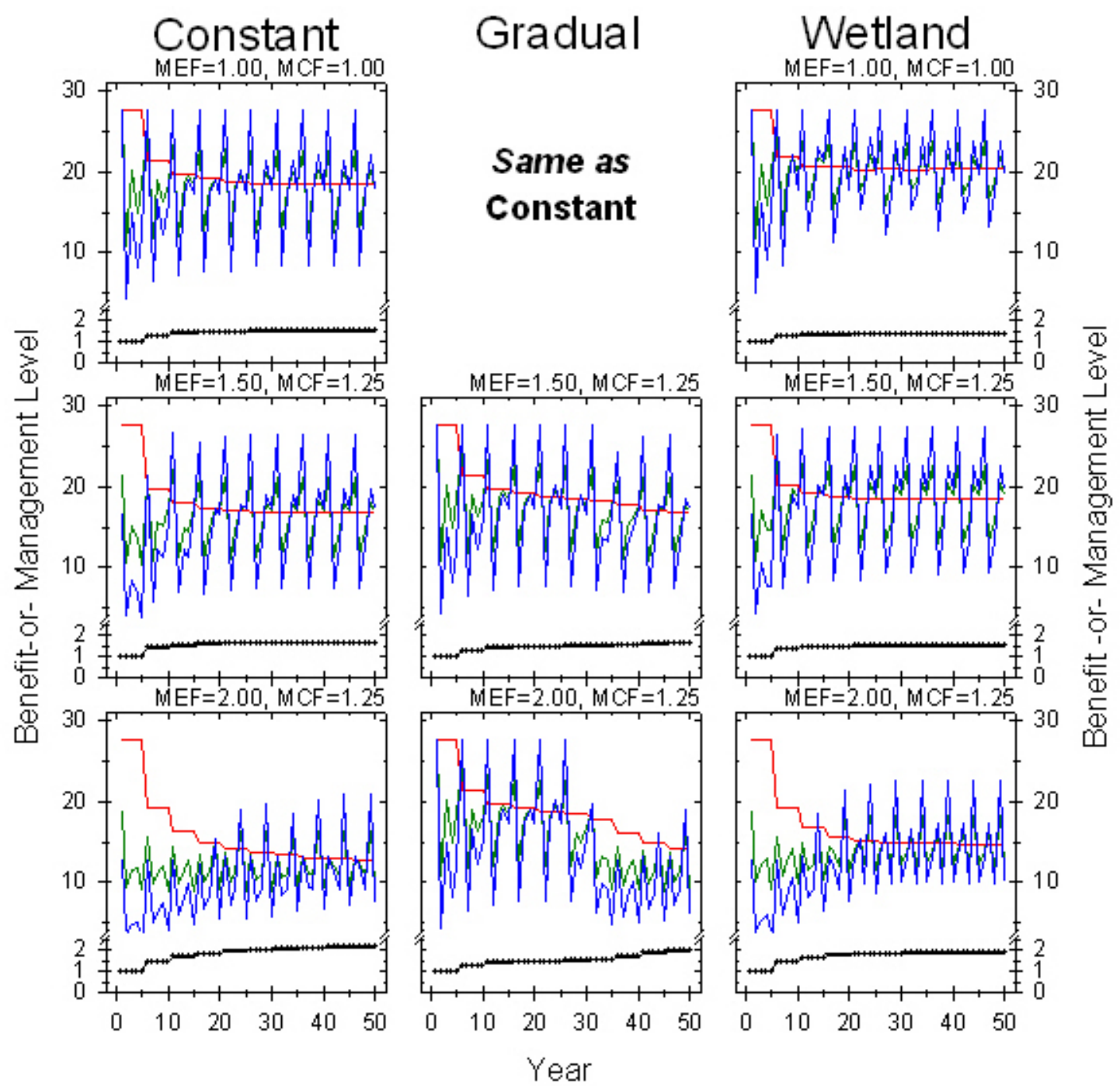

Note: For "constant" simulations, mussel effects were included from yr 1 and remained constant over the 50-yr simulation period. For "gradual" simulations, the model simulated the first 30 yrs without mussels, a gradual mussel invasion from yrs 30-40, and then constant mussel effects until yr 50. For "wetland" simulations, effects of wetland restoration were included and mussel effects were included from yr 1 and remained constant over the 50-yr simulation period. 
Table 1. Sensitivity analysis of $M C F$ for dreissenid mussel simulations with constant values of $M E F$ and $M C F$ over 50 yrs.

\begin{tabular}{cccc}
\hline \hline $\begin{array}{c}\text { Mussel Consumption Factor } \\
(M C F)\end{array}$ & $\begin{array}{c}\text { Mussel Phosphorus Excretion } \\
\text { Factor }(M E F)\end{array}$ & $\begin{array}{c}\text { Final Phosphorus Load } \\
\text { Reduction }(\%)\end{array}$ & Sensitivity \\
\hline 1.00 & 1.00 & 33 & $(\ldots)$ \\
1.25 & 1.50 & 39 & $(\ldots)$ \\
& 2.00 & 53 & $(\ldots)$ \\
1.50 & 1.50 & 37 & 0.26 \\
& 2.00 & 52 & 0.09 \\
1.75 & 1.50 & 36 & 0.19 \\
& 2.00 & 50 & 0.14 \\
2.00 & 1.50 & 35 & 0.17 \\
& 2.00 & 47 & 0.19 \\
\hline
\end{tabular}

Note: Sensitivity was calculated following Jøgensen (1986). (See Eqn. A2.16 in Appendix 2.) The final phosphorus load reduction (\%) after 50 yrs was used as the state variable to determine sensitivity relative to results for identical $M E F$ when $M C F=1.25$. For example, the final phosphorus load reduction for $M E F=1.50, M C F=1.50(37 \%)$ was compared to the final phosphorus load reduction for $M E F=1.50, M C F=1.25(39 \%)$ to determine a sensitivity of 0.26 . Results indicate that the system was not significantly sensitive to the value of $M C F$.

\section{Gradual dreissenid mussel invasion}

During all gradual mussel invasion simulations, the system converged on the pre-mussel attractor immediately before the start of the invasion (Fig. 7 ). As the invasions continued, $B_{e}$ dropped because of increased internal phosphorus recycling, shifting the system to higher phosphorus management levels to alleviate the decrease in quality of freshwater ecosystem services (Fig. 5). Finally, the system approached a new attractor with equalized stakeholder pressures (Fig. 7). In each case, this attractor was identical to the one observed in Fig. 4 during simulations where the post-invasion values for $M E F$ and $M C F$ were used for all $50 \mathrm{yrs}$.

\section{System Perturbation 2: Large Scale Wetland Restoration}

With wetland restoration included, ecosystem resistance still decreased as internal phosphorus recycling attributed to dreissenid mussels increased. However, wetland restoration decreased the likelihood of poor water clarity events, thereby increasing mean $B_{e}$ (Fig. 5), and SES attractors consistently shifted to states characterized by higher $B_{e}$ and less on-site phosphorus management (higher $B_{p}$ ) with the effects of wetland restoration included (Fig. 8). These increases in $B_{e}$ and $B_{p}$ led to $B_{\text {net }}$ values at social-ecological equilibrium 10\%-17\% greater than those found without wetland restoration for similar dreissenid effects. Global $B_{\max }$ with wetland restoration included were $10 \%-15 \%$ higher and required external load reductions an average of $7 \%$ lower than without wetland restoration (Fig. 6). In all cases, the positive difference between the post 
Fig. 6. Five-yr period mean total net benefits $\left(B_{n e t}\right)$ as a function of percent external phosphorus load reduction $(L R)$ with no mussels $(M E F=1.00$ and $M C F=1.00)$ and with mussel excretory and consumptive effects $(M E F>1.00$ and $M C F=1.25)$ for simulations both without (solid lines) and with (dashed lines) wetland restoration.

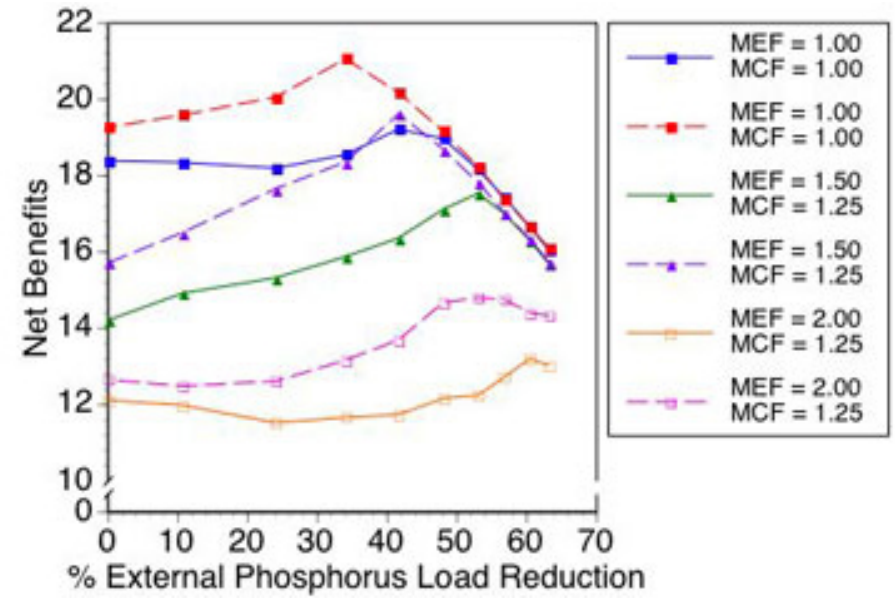

Note: For these results, we ran the model with $L R$ as a forcing function to illustrate the full range of $B_{\text {net }}$ possible at $L R$ between $0 \%$ and $>60 \%$ for each case. In all cases without wetland restoration, socialecological equilibrium occurred at values of $L R(33 \%, 39 \%$ and $53 \%$ for $M E F=1.00,1.50$, and 2.00, respectively; see Fig. 4) that were suboptimal in terms of $B_{n e t}$. We also observed suboptimal compromises for simulations including wetland restoration, with the exception of the case where $M E F=$ 2.00 ( $L R$ at social-ecological equilibrium $=26 \%, 33 \%$, and $46 \%$ for $M E F=1.00,1.50$, and 2.00, respectively; see Fig. 8).

management $B_{\max }$ and $B_{n e t}$ at $L R=0 \%$ was greater with wetland restoration than without. In addition, initial increases in phosphorus management were less likely to result in $B_{n e t}$ declines during wetland restoration simulations (Fig. 6).

\section{DISCUSSION}

\section{Model Assumptions and Limitations}

Modeling complex SESs characterized by an uncountable number of local resource, social pressure, and ecological flows requires the modeler to simplify (Carpenter 2002). Our ecological model is thus a simplification of the Sandusky Bay ecosystem. The aspatial nature of a large well-mixed reactor model makes investigating spatial heterogeneity impossible. Complex phosphorus dynamics including sedimentation and resuspension are not explicitly represented in our model. Like Hein (2006), we do not take into account the impacts of suspended sediments on water clarity, which may be significant during storm events resulting in increased soil erosion (Carpenter et al. 1998), especially in the shallow, highly turbid Sandusky Bay (Conroy 2007). However, we were primarily concerned with poor water clarity events resulting from excessive algal growth in this study and Sandusky Bay shows symptoms of a hypereutrophic system (Conroy 2007).

Our phosphorus management submodel is a simplistic representation of the complex socioeconomic and management systems that characterize western Lake Erie, and it also neglects spatial heterogeneity. Assessing the relationship of two societal groups (affectors and enjoyers) that are completely opposed regarding management pressure fails to capture the diverse perspectives of the human populations 
Fig. 7. Phase space showing 5-yr period mean environmental benefits $\left(B_{e}\right)$ as a function of percent external phosphorus load reduction $(L R)$, which is inversely related to production benefits $\left(B_{p}\right)$, for two simulated gradual mussel invasions that differed in the magnitude of mussel excretory effect (final $M C F$ $=1.25$ in both cases).

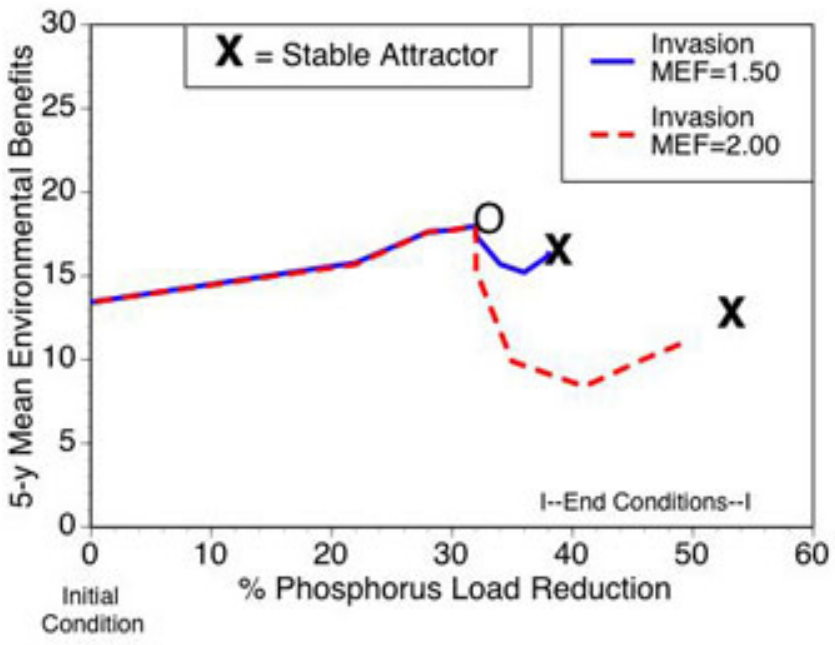

Note: For both simulations, the model simulated the first 30 yrs without mussels, a gradual mussel invasion from yrs 30-40, and then constant mussel effects until yr 50. In each case, the system began at $L R=0$ and management increased with time until the "no mussel" social-ecological equilibrium (labeled "O") was nearly achieved at yr 30. Subsequent decreases in environmental quality because of gradual mussel invasions shifted the system toward new attractors (labeled " $X$ " in bold) identical to those identified in the simulations where $M E F$ and $M C F$ were held constant at post-invasion values (Fig. 4). For the case where the final $M E F=2.00$ and $M C F=1.25$, the system did not achieve equilibrium after $50 \mathrm{yrs}$, hence the gap between the end of the red dotted line and the attractor from Fig. 4.

inhabiting and exploiting the Sandusky watershed and coastline. It also ignores economic behavioral responses to ecological change, e.g., changes in recreational demands or agricultural production decision making. Instead it subsumes all human responses into the management pressure variables. The western Lake Erie system is both complex and unique, so any future restoration efforts will inevitably encounter more site-specific cultural, socioeconomic, and political dynamics characterizing the local communities.

Parameter values in the phosphorus management model are neither known with certainty, nor do they remain static over time, so we have again simplified complex dynamics. In reality, the differing preferences of individuals and influential powers toward lake management policies are constantly evolving under prevailing cultural practices (Kumar and Kumar 2008). The utilitarian approach employed in modeling pressure exerted by stakeholders here is also a simplification because the environment has value to people beyond its immediate and potential utility (Ritov and Kahnman 1997, Kumar and Kumar 2008).

We assume that management changes occur instantaneously after an evaluation of stakeholder benefits. Furthermore, in our model, these management changes are based on instantaneous changes in benefits to both affectors and enjoyers every 5 yrs. One of the primary difficulties in assessing ecosystem management problems in general is that, although benefits arising from polluting production activities are immediate, the associated negative effects to the environment are 
Fig. 8. Phase space showing environmental benefits $B_{e}$ as a function of percent external phosphorus load reduction $(L R)$ with no mussels $(M E F=1.00, M C F=1.00$, blue $)$ and with added mussel excretory and consumptive effects at intermediate $(M E F=1.50, M C F=1.25$, red $)$ and high $(M E F=2.00, M C F=$ 1.25 , green) levels for a Sandusky system with restored wetlands.

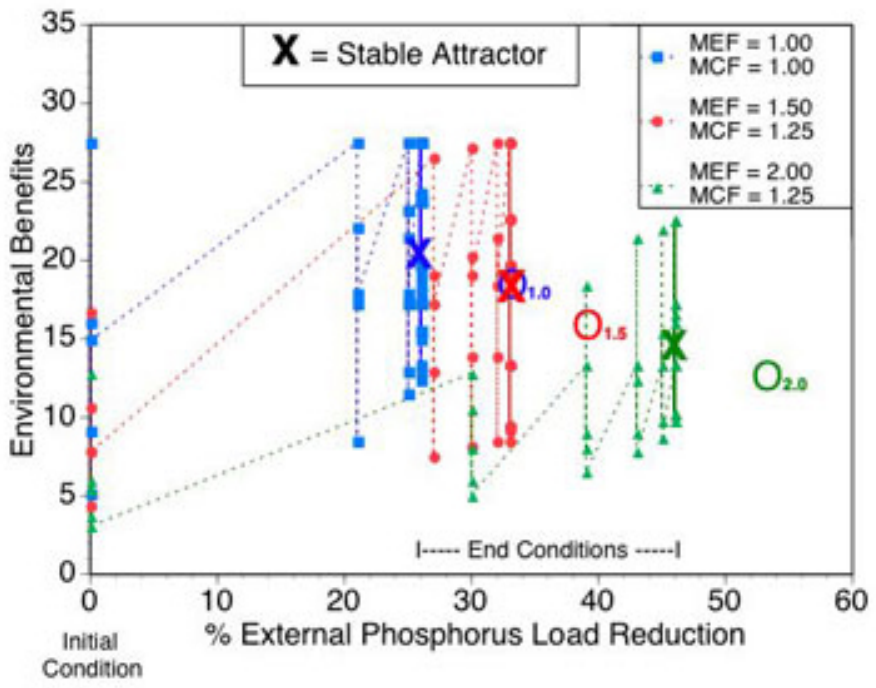

Note: Mussel effects were held constant over the 50 simulation yrs. Individual data points (indicated by various symbols) show each of the 50 simulation yrs. Dotted lines illustrate the system's trajectory with time. In each case, the system began at $L R=0$ and management increased with time until stakeholder compromise (i.e., social-ecological equilibrium) was achieved. SES attractors for the various wetland restoration simulations are labeled with " $\mathrm{X}$ " in bold. Comparable attractors for mussel simulations without wetland restoration are shown as " $\mathrm{O}_{1.0}$ " " $\mathrm{O}_{1.5}$," and " $\mathrm{O}_{2.0}$ " for final $M E F=1.00,1.50$, and 2.00, respectively (same points shown in Fig. 4).

spread out over a long time period. Impatient planners, therefore, tend to worry more about immediate benefits to affectors and less about the long-term benefits to enjoyers (Mäler et al. 2003, Brock and Starrett 2003). We also assume that increases in external phosphorus management are accompanied by certain proportional decreases in $B$, independent of time. For model simulations of $50 \mathrm{yrs}$, this assumption is inaccurate. Future technologies, along with changing energy and material costs, will likely cause variability in the effects of increased nutrient management on affectors. Finally, further research is needed to more accurately represent manager behavior. Stakeholder pressure is only one of many variables affecting management decisions. Existing laws and regulations, budgets, managers' expertise and beliefs, the status quo, and previously created ecosystem management plans also impact decision making.

\section{Limitations of Simulated System Perturbations}

The multiple impacts of dreissenid mussels on ecosystem processes are complex and only approximated by the methods employed here. These simulations were not intended to be the basis of a rigorous investigation of specific ecosystem dynamics, but instead represent a general shift in ecosystem processes because of an invasive species that may have system-wide consequences. Not only is there uncertainty relative to the values of $M E F$ and $M C F$, but we also assume here that dreissenid 
mussel excretion and consumption rates follow temporal patterns exhibited by zooplankton. A separate model of dreissenid mussel growth, abundance, and mortality would better account for temporal dynamics, but such a model was beyond the scope of the current project.

The central limitation of the wetland restoration simulation is the absence of a cost-benefit analysis for the proposed wetland restoration, primarily because economic variables in the model are currently based on a generalized notion of benefits rather than specific values. However, our model provides a starting point for future research on a holistic cost-benefit analysis including wetland restoration cost, ecosystem services benefits, and long-term benefits resulting from decreases in the on-site phosphorus load reductions needed to produce stakeholder phosphorus management compromise. A second limitation is the assumption that wetland restoration at the Sandusky River mouth will only impact Sandusky Bay ecology and socioeconomics through phosphorus reductions. Coastal wetlands also provide numerous ecological functions that produce recreational opportunities for bird watching, sport fishing, and boating, as well as aesthetic benefits for residents and visitors (Folke 1991, Mitsch and Gosselink 2007).

\section{Implications for the Management of Lake Erie}

Pimentel et al. (2000) estimate that nonindigenous species in the United States cause environmental damages totaling approximately US $\$ 137$ billion/yr. Our results suggest that invasive dreissenid mussels may cause economic losses to both ecosystem enjoyers and affectors in terms of current freshwater ecosystem services and future nutrient management, respectively. In our model, decreases in ecosystem resistance to eutrophication caused by dreissenids resulted in an increased number of poor water clarity events, shifting social-ecological equilibrium to a state with higher phosphorus management and lower benefits of all types. Therefore, current phosphorus target loads determined before the dreissenid mussel invasion should be reassessed to ensure that enjoyers in the region do not unjustly carry the entire burden of decreased ecosystem resistance. Our results are similar to those presented by Carpenter et al. (1999b) regarding internal phosphorus loading from sediments. Their model showed that lakes for which eutrophication is irreversible because of high phosphorus recycling from sediments require lower phosphorus target loads than those for which phosphorus recycling is less dominant. Recognizing the importance of internal phosphorus loading to eutrophication control seems essential to successful management.

The external phosphorus load reduction at socialecological equilibria found here for mussel simulations were 6\%-20\% higher compared with the model excluding mussel effects. In addition, we determined that: (1) optimal net benefits occurred at external phosphorus load reductions of $40 \%-60 \%$ depending on the excretory impact of mussels, and (2) whether or not any net benefit resulted from smaller increases in management, i.e., whether the net benefits-management curve was concave or convex, was also dependent on the impact of mussels on phosphorus recycling. Creating more uncertainty, the western Lake Erie ecosystem continues to change. For example, dreissenid mussel community species composition has recently shifted from a zebra mussel-dominated population to one dominated by quagga mussels (Conroy et al. 2005a). More research is needed to assess the full ecological impacts of dreissenids, as well as current changes in community size and composition. Our results, coupled with current ecosystem change, indicate a high degree of uncertainty regarding how much phosphorus management in the Sandusky region is optimal in terms of stakeholder welfare.

Walters (1986) states that, in situations such as this, management decisions are essentially gambles despite any clarification achieved through modeling. If only minor phosphorus load reductions are pursued in western Lake Erie, the ecosystem may fail to respond positively. In this case, economic losses on behalf of affectors because of increased management would not result in higher quality freshwater ecosystem services. More importantly, our results suggest that if the increase in internal phosphorus loading because of mussels has in fact become very large (e.g., $M E F=2.00$, Fig. 6), the likelihood that increased on-site phosphorus management will result in significant net benefits gains is low. Furthermore, net benefits following the invasion of dreissenids may never again reach the pre-invasion level if on-site phosphorus control is the sole management lever. However, in moderate mussel simulations (e.g., $M E F=1.50$ ), net benefits at stakeholder compromise following increased phosphorus management, as well as the global $B_{\max }$ we 
identified, were significantly higher than at the status quo management level. Hence, increased management of external phosphorus loading potentially could provide economic benefits to the region. Ludwig (2002) argues that the substantial and irreducible uncertainty of many ecological situations leaves the framework of optimal decision making poorly equipped to evaluate alternative management options. Dreissenid mussels complicate identifying optimal phosphorus management approaches for the Lake Erie region, but this should not paralyze managers.

Aside from increased on-site management of phosphorus export in the agricultural sector, ecosystem restoration strategies should also be explored as a means to rehabilitate Lake Erie (Mitsch and Wang 2000). Using an ecologicaleconomic model, Hein (2006) found that large-scale lake restoration coupled with reductions in external phosphorus loading was a more cost-effective strategy than one based on reducing external nutrient inputs alone, a conclusion that our wetland restoration simulations also supports. Management strategies that provide increased pollution buffers between opposing stakeholders, such as the potential $12 \%$ decrease in phosphorus entering Sandusky Bay because of wetland restoration at the mouth of the Sandusky River, appear to be essential for increasing regional net benefits.

External phosphorus management is only one of many policy levers for the management of Lake Erie. We emphasize the need to manage the ecosystem as a system and to consider that strong management levers, such as phosphorus control, may not exist (Conroy 2007). Aggressive external phosphorus management may also create excessive tension between ecosystem affectors and enjoyers when ecosystem resistance is declining, as illustrated in our dreissenid mussel simulations. Furthermore, additional nonindigenous species are expected to enter the Great Lakes in the future (Ricciardi 2006). The United States Environmental Protection Agency's (USEPA) National Center for Environmental Assessment recently identified 58 species as having a moderate or high potential to spread and cause ecological impacts to the Great Lakes (USEPA 1999). Of these, Lake Erie is particularly vulnerable to 14 invaders through ballast water discharges from ships traveling through the St. Lawrence Seaway, most originating in Canada or Western Europe (USEPA 2008). Researchers have suggested that climate change may also drastically alter the resistance of lake ecosystems to eutrophication (Malmaeus et al. 2006). Our results indicate that variations in external phosphorus loading attributed to climate can have large effects on environmental benefits. This highlights that: (1) climate change may alter freshwater ecosystem services, (2) static management levels do not produce static freshwater ecosystem services, and (3) it is unlikely that increased management of external phosphorus loading will eliminate fluctuations in environmental quality in Lake Erie. To achieve sustainability in western Lake Erie, the development of management strategies focused on increasing system resistance to eutrophication is essential (Walker et al. 2002). In addition to direct phosphorus control and largescale wetland restoration, taking steps to slow the invasion of more nonindigenous species, control climate change (Conroy 2007), and increase sequestration of nutrients within the upstream watershed appear to be critical to both ecological and socioeconomic welfare in Lake Erie.

Lastly, managers should be cautious of inefficient phosphorus management compromise in western Lake Erie. Scheffer et al. (2000) state that in certain cases an ecosystem management compromise between opposing stakeholders may be a bad solution because it represents a situation with low overall net benefits. In almost all of our simulations, social-ecological equilibrium in the Sandusky system occurred at an external phosphorus load reduction that was suboptimal in terms of net benefits. Therefore, it seems unlikely that decision making driven by opposing sociopolitical forces will produce optimal returns, especially in a SES with complex, dynamic ecosystem response to management such as western Lake Erie.

\section{Social-Ecological System Stability}

In coupled SESs, cross-system interactions can occur at several temporal, spatial, and organizational scales, making the presence of multiple equilibria, regime shifts, and transient dynamics more likely than in uncoupled systems (Chen et al. 2009). Moving away from the classic "balance of nature" paradigm in ecology that is based on the concept of stable equilibrium, researchers since the 1970s have been developing a perspective of managed ecosystems as inherently unpredictable and uncontrollable, and of ecosystem processes as nonlinear, characterized by surprises, and multi- 
equilibrium or nonequilibrium (Holling 1973, Walters 1986, Holling 1996, Wallington et al. 2005). This new perspective is supported by our results, which cast doubt on the existence of a single stable state in the western Lake Erie SES. Our results illustrate that several transient stable states are possible for changing SESs because of unforeseeable ecological perturbations and the human capacity to increase system resistance through ecosystem restoration. Put simply, SESs are open and dynamic.

Whether or not the Sandusky system will truly gravitate toward any of the attractors identified here is uncertain. (For a discussion of nonlinear socioeconomic behavior in lake systems, see Iwasa et al. 2007.) In fact, Pahl-Wostl et al. (2008) suggest that the primary problem faced by researchers concerned with sustainable water resources management is a lack of understanding of how governance and cultural systems are structured and interact with ecological systems. In future applications of our model, we intend to pursue empirical agent-based modeling (Parker et al. 2003, An et al. 2005), participatory modeling (van den Belt 2004, Prell et al. 2007, Voinov and Gaddis 2008), and an expansion of the economic dynamics represented to better capture human dynamics in a social-ecological context. However, even if the basis of management decision making in our model were expanded, uncertainty about attractors will remain. In a world where creative human choice is a constant source of an unknowable future (Wiseman 1989, Buchanan and Vanberg 1994, Massey 1999) and unforeseeable ecological perturbation is common (Holling 1996), the concept of stable equilibrium in a social-ecological context seems purely theoretical.

\section{CONCLUSION}

We developed an integrated social-ecological model that included three dynamic feedback loops among freshwater ecology, ecosystem services, and phosphorus management in Lake Erie's Sandusky Bay and watershed. Our simulations suggested that invasive dreissenid mussels have shifted the point of regional stakeholder compromise to a state characterized by higher phosphorus management and decreased environmental quality. Using our model, we also illustrated that large-scale wetland restoration is one potential management option available to increase ecosystem resistance to eutrophication and decrease tension between opposing stakeholders. We recommend that future modeling efforts focused on lacustrine SESs emphasize site-specific perturbation over equilibrium, highlighting the various pathways open to evolutionary systems. Identifying these pathways can provide managers with essential guidance needed to formulate and implement systemic management plans that build system resistance to undesirable change and that are both flexible and sustainable in an unknowable future.

Responses to this article can be read online at: http://www.ecologyandsociety.org/voll5/iss 1/art20/ responses/

\section{Acknowledgments:}

This research was supported through grants from the U.S. National Science Foundation Biocomplexity Program Grant DEB-0410336, the U.S. National Oceanic and Atmospheric Administration, the Ohio Sea Grant Program, and the Ohio Agricultural and Research Development Center Interdisciplinary Seed Grant Program. Support was also partially provided to E. D. Roy during the preparation of this manuscript by a Graduate Student Fellowship at The Ohio State University. Collection of field data was sponsored primarily by the Ohio Lake Erie Protection Fund (Grant No. 04-16) administered by the Ohio Lake Erie Commission with additional funds provided by the Franz. Theodore Stone Laboratory and the Ohio Sea Grant College Program. Funds for additional sample processing (State Project FADX09) and to support J. D. Conroy during the preparation of this manuscript (State Project FADB02) were provided by the Ohio Department of Natural Resources, Division of Wildlife as part of the Federal Aid in Sport Fish Restoration Program (Project F-69-P, Sport Fish Management in Ohio), administered jointly by the United States Fish and Wildlife Service and the Division of Wildlife.

\section{LITERATURE CITED}

An, L., M. Linderman, J. Qi, A. Shortridge, and J. Liu. 2005. Exploring complexity in a humanenvironment system: an agent-based spatial model 
for multidisciplinary and multiscale integration. Annals of the Association of American Geographers 95(1):54-79.

Ara, S. 2007. The influence of water quality on the demand for residential development around Lake Erie. Dissertation. The Ohio State University, Columbus, Ohio, USA.

Arnott, D. L., and M. J. Vanni. 1996. Nitrogen and phosphorus recycling by the zebra mussel (Dreissena polymorpha) in the western basin of Lake Erie. Canadian Journal of Fisheries and Aquatic Sciences 53:646-659.

Baker, D. B., and M. Ostrand. 2000. Sandusky River watershed resource inventory. Sandusky River Watershed Coalition, Fremont, Ohio, USA.

Brock, W. A., and D. Starrett. 2003. Managing systems with non-convex positive feedback. Environmental and Resource Economics 26:575602.

Buchanan, J. M., and V. J. Vanberg. 1994. The market as a creative process. Pages 315-335 in D. M. Hausman, editor. The philosophy of economics: an anthology. Cambridge University Press, New York, New York, USA.

Burns, N. M., D. C. Rockwell, P. E. Bertram, D. M. Dolan, and J. J. H. Cibrowski. 2005. Trends in temperature, Secchi depth, and dissolved oxygen depletion rates in the central basin of Lake Erie, 1983-2002. Journal of Great Lakes Research 31 (2):35-49.

Byers, R. E., and R. I. C. Hansell. 1996. Implications of semi-stable attractors for ecological modelling. Ecological Modelling 89:59-65.

Carpenter, S. R. 2002. Ecological futures: building an ecology of the long now. Ecology 83(8):20692083.

Carpenter, S. R., W. A. Brock, and P. Hansen. 1999a. Ecological and social dynamics in simple models of ecosystem management. Conservation Ecology 3(2):4. [online] URL: http://www.consecol. org/vol3/iss2/art4/.

Carpenter, S. R., N. F. Caraco, D. L. Correll, R. W. Howarth, A. N. Sharpley, and V. H. Smith.
1998. Nonpoint pollution of surface waters with phosphorus and nitrogen. Ecological Applications 8:559-568.

Carpenter, S. R., D. Ludwig, and W. A. Brock. $1999 \mathrm{~b}$. Management of eutrophication for lakes subject to potentially irreversible change. Ecological Applications 9(3):751-771.

Center for Lake Erie Area Research (CLEAR). 1975. Aquatic ecology investigations of a potential power plant site on Sandusky Bay. Final Report to the American Electric Power Service Corporation. CLEAR Technical Report No. 38. Ohio Sea Grant College Program, Columbus, Ohio, USA.

Charlton, M. N., and J. E. Milne. 2004. Review of thirty years of change in Lake Erie water quality. National Water Research Institute (NWRI) Contribution No. 04-167. National Water Research Institute, Aquatic Ecosystem Management Research Branch, Burlington, Ontario, Canada.

Charlton, M. N., J. E. Milne, W. G. Booth, and F. Chiocchio. 1993. Lake Erie offshore in 1990: restoration and resilience in the central basin. Journal of Great Lakes Research 19:291-309.

Chen, Y., E. G. Irwin, and C. Jayaprakash. 2009. Dynamic modeling of environmental amenitydriven migration with ecological feedbacks. Ecological Economics 68:2498-2510.

Codd, G. A. 2000. Cyanobacterial toxins, the perception of water quality, and the prioritization of eutrophication control. Ecological Engineering 16:51-60.

Conroy, J. D. 2007. Testing the algal loading hypothesis: the importance of Sandusky River phytoplankton inputs to offshore Lake Erie processes. Dissertation. The Ohio State University, Columbus, Ohio, USA.

Conroy, J. D., and D. A. Culver. 2005. Do dreissenid mussels affect Lake Erie ecosystem stability processes? American Midland Naturalist 153:20-32.

Conroy, J. D., W. J. Edwards, R. A. Pontius, D. D. Kane, H. Zhang, J. F. Shea, J. N. Richey, and D. A. Culver. 2005a. Soluble nitrogen and phosphorus excretion of exotic freshwater mussels 
(Dreissena spp.): potential impacts for nutrient remineralisation in western Lake Erie. Freshwater Biology 50:1146-1162.

Conroy, J. D., D. D. Kane, and D. A. Culver. 2008. Declining Lake Erie ecosystem health: evidence from a multi-year, lake-wide plankton study. Pages 369-408 in M. Munawar and R. T. Heath, editors. Checking the Pulse of Lake Erie. Ecovision World Monograph Series, Aquatic Ecosystem Health and Management Society (AEHMS), Burlington, Ontario, Canada.

Conroy, J. D., D. D. Kane, D. M. Dolan, W. J. Edwards, M. N. Charlton, and D. A. Culver. 2005b. Temporal trends in Lake Erie plankton biomass: roles of external phosphorus loading and dreissenid mussels. Journal of Great Lakes Research 31(2):89-110.

Cooke, G. D., E. B. Welch, S. A. Peterson, and P. R. Newroth. 1993. Restoration and management of lakes and reservoirs. Lewis, Boca Raton, Florida, USA.

Costanza, R. 1989. Model goodness of fit: a multiple resolution procedure. Ecological Modelling 47:199-215.

Costanza, R., and A. Voinov. 2001. Modeling ecological and economic systems with STELLA: part III. Ecological Modelling 143(1-2):1-7.

DeAngelis, D. L., and J. C. Waterhouse. 1987. Equilibrium and nonequilibrium concepts in ecological models. Ecological Monographs 57 (1):1-21.

Deleuze, G., and F. Guattari. 1987. A thousand plateaus: capitalism and schizophrenia. University of Minnesota Press, Minneapolis, Minnesota, USA.

DiToro, D. M., N. A. Thomas, C. E. Herdendorf, R. P. Winfield, and J. P. Connolly. 1987. A post audit of a Lake Erie eutrophication model. Journal of Great Lakes Research 13(4):801-825.

Dolan, D. M. and K. P. McGunagle. 2005. Lake Erie total phosphorus loading analysis and update: 1996-2002. Journal of Great Lakes Research 31 (2):11-22.

Edwards, W. J., C. R. Rehmann, E. McDonald, and D. A. Culver. 2005. The impact of a benthic filter feeder: limitations imposed by the physical transport of algae to the benthos. Canadian Journal of Fisheries and Aquatic Sciences 62:205-214.

Folke, C. 1991. The societal value of wetland lifesupport. Pages 141-171 in C. Folke and T. Kaberger, editors. Linking the natural environment and the economy. Kluwer, Dordrecht, The Netherlands.

Forster, D. L., R. P. Richards, D. B. Baker, and E. N. Blue. 2000. EPIC modeling of the effects of farming practice changes on water quality in two Lake Erie watersheds. Journal of Soil and Water Conservation 55(1): 85-96.

Grimm, V., and C. Wissel. 1997. Babel, or the ecological stability discussions: an inventory and analysis of terminology and a guide for avoiding confusion. Oecologia 109:323-334.

Hebert, P. D. N., B. W. Muncasterm, and G. L. Mackie. 1989. Ecological and genetic studies on Dreissena polymorpha (Pallas): a new mollusk in the Great Lakes. Canadian Journal of Fisheries and Aquatic Sciences 46:1587-1591.

Hecky, R. E., R. E. H. Smith, D. R. Barton, S. J. Guildford, W. D. Taylor, M. N. Charlton, and T. Howell. 2004. The nearshore phosphorus shunt: a consequence of ecosystem engineering by dreissenids in the Laurentian Great Lakes. Canadian Journal of Fisheries and Aquatic Sciences 61:1285-1293.

Hein, L. 2006. Cost-efficient eutrophication control in a shallow lake ecosystem subject to two steady states. Ecological Economics 59:429-439.

Holling, C. S. 1973. Resilience and stability of ecological systems. Annual Reviews of Ecology and Systematics 4:1-23.

Holling, C. S. 1996. Surprise for science, resilience for ecosystems, and incentives for people. Ecological Applications 6(3):733-735.

Irwin, E. G., and J. Geoghegan. 2001. Theory, data, methods: developing spatially explicit economic models of land use change. Agriculture, Ecosystems and Environment 85:7-23.

Iwasa, Y., T. Uchida, and H. Yokomizo. 2007. Nonlinear behavior of the socio-economic 
dynamics for lake eutrophication control. Ecological Economics 63:219-229.

Jøgensen, S. E. 1982. Modelling the eutrophication of shallow lakes. Pages 125-155 in Proceedings of the International Scientific Workshop on Ecosystem Dynamics in Freshwater Wetlands and Shallow Water Bodies. Centre of International Projects GKNT, Moscow, USSR.

Jøgensen, S. E. 1986. Developments in environmental modelling 9: fundamentals of ecological modelling. Elsevier, New York, New York, USA.

Knetsch, J. L. 1997. Reference states, fairness, and choice of measure to value environmental changes. Pages 13-32 in M. H. Bazerman et al., editors. Environment, ethics, and behavior. New Lexington, San Francisco, California, USA.

Kumar, M., and P. Kumar. 2008. Valuation of the ecosystem services: a psycho-cultural perspective. Ecological Economics 64:808-819.

Limno-Tech, Inc. 2000. Ecosystem model for the Lake Michigan mass balance study: model documentation final report. Great Lakes National Program Office, United States Environmental Protection Agency, Chicago, Illinois, USA.

Loftus, T. T., D. B. Baker, J. V. Setzler, J. Crumrine, and C. Riddle. 2006. Honey Creek watershed action plan. Sandusky River Watershed Coalition and the National Center for Water Quality Research, Heidelberg University, Tiffin, Ohio, USA.

Ludwig, D. 2002. The era of management is over. Ecosystems 4:758-764.

Ludwig, D., S. R. Carpenter, and W. A. Brock. 2003. Optimal phosphorus loading for a potentially eutrophic lake. Ecological Applications 13 (4):1135-1152.

Magee, S., W.A. Brock, and L. Young. 1989. Black hole tariffs and endogenous policy theory. Cambridge University Press, New York, New York, USA.

Makarewicz, J. C., and P. E. Bertram. 1991. Evidence for the restoration of the Lake Erie ecosystem. Bioscience 41:216-223.
Makarewicz, J. C., P. Bertram, and T. W. Lewis. 2000. Chemistry of the offshore surface waters of Lake Erie: pre- and post-Dreissena introduction (1983-1993). Journal of Great Lakes Research 26 (1):82-93.

Mäler, K. G., A. Xepapadeas, and A. de Zeeuw. 2003. The economics of shallow lakes. Environmental and Resource Economics 26:603624.

Malmaeus, J. M., T. Blenckner, H. Markensten, and I. Persson. 2006. Lake phosphorus dynamics and climate warming: a mechanistic model approach. Ecological Modelling 190:1-14.

Martin, J. F., E. Reyes, G. P. Kemp, H. Mashriqui, and J. W. Day. 2002. Landscape modeling of the Mississippi Delta. Bioscience 52 (4):357-365.

Massey, D. 1999. Space-time, 'science' and the relationship between physical geography and human geography. Transactions of the Institute of British Geographers 24:261-276.

Matisoff, G., and J. J. H. Ciborowski. 2005. Lake Erie trophic status collaborative study. Journal of Great Lakes Research 31 (2):1-10.

May, B., and J. E. Marsden. 1992. Genetic identification and implications of another invasive species of dreissenid mussel in the Great Lakes. Canadian Journal of Fisheries and Aquatic Sciences 49:1501-1506.

McCormick, M. J. 1996. Lake Erie water temperature data: Sandusky Bay, Ohio 1961-1993. National Oceanic and Atmospheric Administration Technical Memorandum ERL GLERL-98. National Oceanic and Atmospheric Administration, United States Department of Commerce, Ann Arbor, Michigan, USA.

McGucken, W. 2000. Lake Erie rehabilitated: controlling cultural eutrophication, 1960s-1990s. University of Akron Press, Akron, Ohio, USA.

Michael, H. J., K. J. Boyle, and R. Bouchard. 1996. Water quality affects property prices: a case study of selected Maine lakes. Maine Agricultural and Forest Experiment Station Report Number 398. University of Maine, Orono, Maine, USA. 
Mitsch, W. J., and J. G. Gosselink. 2007. Wetlands. Fourth edition. Wiley, Hoboken, New Jersey, USA.

Mitsch, W. J., and N. Wang. 2000. Large-scale coastal wetland restoration on the Laurentian Great Lakes: determining the potential for water quality improvement. Ecological Engineering 15:267282.

National Center for Water Quality Research (NCWQR). Water quality data for Ohio watersheds. Heidelberg University, Tiffin, Ohio, USA.

National Research Council (NRC). 1992. Restoration of aquatic ecosystems: science, technology, and public policy. National Academy, Washington, D.C., USA.

Pahl-Wostl, C., E. Mostert, and D. Tâbara. 2008. The growing importance of social learning in water resources management and sustainability science. Ecology and Society 13(1): 24. [online] URL: http: //www.ecologyandsociety.org/vol13/iss1/art24/

Parker, D. C., S. M., Manson, M. A. Janssen, M. J. Hoffmann, and P. Deadman. 2003. Multiagent system models for the simulation of land-use and land-cover change: a review. Annals of the Association of American Geographers 93(2):314337.

Pimentel, D., L. Lach, R. Zuniga, and D. Morrison. 2000. Environmental and economic costs of nonindigenous species in the United States. Bioscience 50(1):53-65.

Porta, D., M.A. J. Fitzpatrick, and G. D. Haffner. 2005. Annual variability of phytoplankton primary production in the western basin of Lake Erie (20022003). Journal of Great Lakes Research 31(2):6371.

Prell, C., K. Hubacek, M. Reed, C. Quinn, N. Jin, J. Holden, T. Burt, M. Kirby, and J. Sendzimir. 2007. If you have a hammer everything looks like a nail: traditional versus participatory model building. Interdisciplinary Science Reviews $\mathbf{3 2}$ (3):263-282.

Prigogine, I., and I. Stengers. 1984. Order out of chaos: man's new dialogue with nature. Heinemann, London, UK.
Raikow, D. F., O. Sarnelle, A. E. Wilson, and S. K. Hamilton. 2004. Dominance of the noxious cyanobacterium Microcistis aeruginosa in lownutrient lakes is associated with exotic zebra mussels. Limnology and Oceanography 49:482487.

Reyes, E., M. L. White, J. F. Martin, G. P. Kemp, J. W. Day, and V.Aravamuthan. 2000. Landscape modeling of coastal habitat change in the Mississippi Delta. Ecology 81(8):2331-2349.

Ricciardi, A. 2006. Patterns of invasion of the Laurentian Great Lakes in relation to changes in vector activity. Diversity and Distributions 12:425433.

Richards, R. P., and D. B. Baker. 1985. Assimilation and flux of sediments and pollutants in the Sandusky River estuary, Sandusky Bay, and the adjacent nearshore zone of Lake Erie. Final Report to the National Oceanic and Atmospheric Administration. Water Quality Laboratory Papers, Heidelberg University, Tiffin, Ohio, USA.

Riddle, C. M., D. B. Baker, and J. P. Crumine. 2006. Sandusky River-Tiffin watershed action plan. Sandusky River Watershed Coalition and the National Center for Water Quality Research, Heidelberg University, Ohio, USA.

Ritov, I., and D. Kahnman. 1997. How people value the environment. Pages 33-51 in M. H. Bazerman. Environment, ethics, and behavior. New Lexington, San Francisco, California, USA.

Sas, H. 1989. Lake restoration by reduction of nutrient loading: expectations, experiences, and extrapolations. Academia, St. Augustin, Germany.

Scheffer, M., W. A. Brock, and F. Westley. 2000. Socioeconomic mechanisms preventing optimum use of ecosystem services: an interdisciplinary theoretical analysis. Ecosystems 3:451-471.

Steinnes, D. N. 1992. Measuring the economic value of water quality: the case of lakeshore land. Annals of Regional Science 26:171-176.

Stonehouse, D. P. 1999. Economic evaluation of on-farm conservation practices in the Great Lakes region of North America. Environmetrics 10:505520 . 
Thornes, J. B. 1983. Evolutionary geomorphology. Geography 68:225-235.

United States Environmental Protection Agency (USEPA). 2008. Predicting future introductions of nonindigenous species to the Great Lakes. National Center for Environmental Assessment Technical Report EPA/600/R-08/066F. Washington, D.C., USA. [online] URL: http://cfpub.epa.gov/ncea/cfm/ recordisplay.cfm?deid=190305.

United States Environmental Protection Agency (USEPA). 2009. Cuyahoga River area of concern Great Lakes areas of concern. Washington, D.C., USA. [online] URL: http://www.epa.gov/glnpo/aoc/ cuyahoga.html.

van den Belt, M. 2004. Mediated modeling: a systems dynamics approach to environmental consensus building. Island Press, Washington, D. C., USA.

Vanderploeg, J. R. Liebig, W. W. Carmichael, M. A. Agy, T. H. Johengen, G. L. Fahnenstiel, and T. F. Nalepa. 2001. Zebra mussel (Dreissena polymorpha) selective filtration promoted toxic Microcystis blooms in Saginaw Bay (Lake Huron) and Lake Erie. Canadian Journal of Fisheries and Aquatic Sciences 58(6):1208-1221.

Varian, H. R. 1992. Microeconomic analysis. Third edition. W. W. Norton, New York, New York, USA.

Vincent, R. K., X. Qin, R. M. L. McKay, J. Miner, K. Czajkowski, J. Savino, and T. Bridgeman. 2004. Phycocyanin detection from LANDSAT TM data for mapping cyanobacterial blooms in Lake Erie. Remote Sensing of the Environment 89:381392.

Voinov, A., and E. J. B. Gaddis. 2008. Lessons for successful participatory watershed modeling: a perspective from modeling practitioners. Ecological Modelling 216:197-207.

Walker, B., S. Carpenter, J. Anderies, N. Abel, G. Cumming, M. Janssen, L. Lebel, J. Norberg, G. D. Peterson, and R. Pritchard. 2002. Resilience management in social-ecological systems: a working hypothesis for a participatory approach. Conservation Ecology 6(1): 14. [online] URL: http ://www.ecologyandsociety.org/vol6/iss1/art14.
Walker, B., C. S. Holling, S. R. Carpenter, and A. Kinzig. 2004. Resilience, adaptability and transformability in social-ecological systems. Ecology and Society 9(2): 5. [online] URL: http://w ww.ecologyandsociety.org/vol9/iss2/art5

Wallington, T. J., R. J. Hobbs, and S. A. Moore. 2005. Implications of current ecological thinking for biodiversity conservation: a review of the salient issues. Ecology and Society 10(1): 15 [online] URL: http://www.ecologyandsociety.org/vol10/iss1/art15

Walters, C. 1986. Adaptive management of renewable resources. Macmillan, New York, New York, USA.

Wen, Y. H., and R. H. Peters. 1994. Empirical models of phosphorus and nitrogen excretion rates by zooplankton. Limnology and Oceanography 39 (7):1669-1676.

Wetzel, R. G. 2001. Limnology: lake and river ecosystems. Third edition. Academic Press, San Diego, California, USA.

White, P. S., and J. L. Walker. 1997. Approximating nature's variation: selecting and using reference information for restoration ecology. Restoration Ecology 5(4):338-349.

Wilson, M. A., and S. R. Carpenter. 1997. Economic valuation of freshwater ecosystem services in the United States: 1991-1997. Ecological Applications 9(3):772-783.

Wirl, F. 2004. Thresholds in concave renewable resource models. Ecological Economics 48:259267.

Wiseman, J. 1989. Cost, choice, and political economy. Edward Elgar, Aldershot, UK.

Zhang, H. 2006. Ecological modeling of the lower trophic levels of Lake Erie. Dissertation. The Ohio State University, Columbus, Ohio, USA. 


\section{Appendix 1. Model Forcing Functions}

\section{Please click here to download file 'appendixl.pdf'.}




\section{Appendix 2. Sandusky Bay Ecological Unit Model}

\section{Please click here to download file 'appendix2.pdf'.}




\section{Appendix 3. Phosphorus Management Model}

\section{Please click here to download file 'appendix3.pdf'.}




\section{Appendix 4. Model Parameters}

\section{Please click here to download file 'appendix4.pdf'.}

